\title{
Accuracy of Ventricular Catheter Tip Placement Using Freehand Placement
}

\author{
DM Arman ${ }^{1}$, Sheikh Muhammad Ekramullah², Sudipta Kumer Mukherjee ${ }^{3}$, \\ Samantha Afreen ${ }^{4}$, Md. Anwarul Hoque Faraji ${ }^{5}$, Kazi Nur Asfia ${ }^{6}$, MA Quddus Mia ${ }^{7}$, \\ Md. Aslam Hossain ${ }^{8}$, Mohammad Abul Kalam Azad ${ }^{9}$

\begin{abstract}
${ }^{1}$ Assistant Professor, Department of Paediatric Neurosurgery, National Institute of Neurosciences and Hospital, Dhaka, Bangladesh; ${ }^{2}$ Professor \& Head, Department of Paediatric Neurosurgery, National Institute of Neurosciences and Hospital, Dhaka, Bangladesh; ${ }^{3}$ Assistant Professor, Department of Paediatric Neurosurgery, National Institute of Neurosciences and Hospital, Dhaka, Bangladesh; ${ }^{4}$ Registrar, Department of Paediatric Neurosurgery, National Institute of Neurosciences and Hospital,Dhaka, Bangladesh; ${ }^{5}$ Assistant professor, Department of Nephrology, National Institute of Kidney Diseases \& Urology, Dhaka, Bangladesh; ${ }^{6}$ Assistant Professor, Department of Neuroanaesthesia, National Institute of Neurosciences and Hospital, Dhaka, Bangladesh; ${ }^{7}$ Consultant, Department of Neuro-anaesthesia, National Institute of Neurosciences and Hospital, Dhaka, Bangladesh; ${ }^{8}$ Assistant Professor, Department of General Surgery, Sheikh Hasina Medical College, Tangail, Bangladesh; ${ }^{9}$ Assistant Professor, Department of Anaesthesia, BIHS
\end{abstract} \\ General Hospital, Dhaka, Bangladesh
}

[Received: 10 October 2018; Accepted: 12 November 2018; Published: 1 January 2019]

\begin{abstract}
Background: Inaccurate placement of VP shunt catheter is related to shunt failure. Objective: The objective of this study was to determine the accuracy of ventricular catheter placement during ventriculoperitoneal shunt operations using the freehand technique. Methodology: This prospective observational study included all patients from a single institution who underwent a ventriculoperitoneal shunt procedure in which a new ventricular catheter was placed between September 2013 and August 2016 for a period of three (03) years. Data abstracted for each patient included age, sex, diagnosis, site and side of ventricular catheter placement. Postoperative CT scan images were reviewed for accuracy of ventricular catheter placement. Results: There were 140 patients included in the study; accuracy ventricular catheter tip placement were 55 (39.28\%) using freehand technique. Conclusion: Mechanical malfunction and infection are the most significant problems associated with shunts for the treatment of hydrocephalus. [Journal of National Institute of Neurosciences Bangladesh, 2019;5(1): 59-63]
\end{abstract}

Keywords: Hydrocephalus; ventriculoperitoneal shunt;ventricular catheter placement; accuracy

Correspondence: Dr. DM Arman, Assistant Professor, Department of Paediatric Neurosurgery, National Institute of Neurosciences \& Hospital, Dhaka, Bangladesh; Email: armandmdr@yahoo.com; cell: +8801745771780

Conflict of interest: There is no conflict of interest relevant to this paper to disclose.

Funding agency: This research project was not funded by any group or any institution.

Contribution to authors: Arman DM, Ekramullah SM contributed from the protocol preparation, data collection up to report writing. Manuscript writing was performed by Mukherjee SK, Afreen S, Quddus MA.Statistical analysis was performed by Arman DM. Asfia KN, Aslam M, Faraji MAH, Azad MAK involved in revision of manuscript.

How to cite this article:Arman DM, Ekramullah SM, Mukherjee SK, Afreen S, Faraji MAH, Quddus MA, Asfia KN, Aslam M, Azad MAK. Accuracy of Ventricular Catheter Tip Placement Using Freehand technique. J NatlInstNeurosci Bangladesh, 2019;5(1): 59-63

Copyright: (C2019. Arman et al. Published by Journal of National Institute of Neurosciences Bangladesh. This article is published under the Creative Commons CC BY-NC License (https://creativecommons.org/licenses/by-nc/4.0/). This license permits use, distribution and reproduction in any medium, provided the original work is properly cited, and is not used for commercial purposes.

\section{Introduction}

Ventriculoperitoneal shunt placement is one of the most commonly performed neurosurgical procedures and it is a standard surgical procedure for hydrocephalus. Despite advances in shunt catheter materials and the valves used, there remains a high rate of shunt failure. Approximately $30.0 \%$ to $50.0 \%$ of shunt surgeries for hydrocephalus require shunt revision within the first 12 months ${ }^{1}$.Mechanical dysfunction remains the most common cause of this failure ${ }^{2}$.

The most common reason for proximal catheter failure is believed to be obstruction of the catheter by the choroid plexus ${ }^{3}$ and by debris from choroid plexus and ependymal. Optimal catheter placement should help reduce this risk, everything should be done to optimize catheter placement. Correct placement the catheter tip is essential for long term VP shunt function. Most ventricular catheters are placed using anatomical 
landmarks in a freehand fashion, although adjuncts are available, including stereotactic neuro-navigation and intraoperative ultrasonography. In this study, the accuracy of ventricular catheter placement was performed by using anatomical landmark-guided freehand placement.

Multiple studies have concluded that ventricular catheters placed into the frontal horn or trigone, away from the choroid plexus and ventricular walls, result in a significant improvement in shunt survival ${ }^{4}$. If reliable surgical techniques for accurate placement of ventricular catheters can be developed, shunt survival may improve. Conventional shunt insertion techniques rely on anatomical landmarks to determine catheter trajectory into the ventricle. The depth of catheter insertion is determined by a variety of methods including preoperative imaging, endoscopy, and the flow of CSF from the catheter. These techniques result in favorable catheter placement in approximately one-third to two-thirds of cases ${ }^{5-10}$. The target was defined as the ipsilateral frontal horn or trigone.

Proximal catheter obstruction is known to be the most common cause of malfunctioning of ventriculoperitoneal (VP) shunt followed by infection. Thus, the chief concern when inserting a VP shunt should be the precise placement of the ventricular catheter. The standard technique of ventricular catheter placement depends on anatomic landmarks; however, this may not be satisfactory to consistently ensure optimal positioning of the ventricular catheter. The optimal position of the catheter tip was focused to reduce potential occlusion of proximal catheter by ventricular parenchyma or choroidal tissues $^{2}$. Many studies including Tuliet al ${ }^{11}$ have shown that a ventricular catheter tip surrounded by cerebrospinal fluid (CSF) could decrease the risk of shunt failure.

In a prospective observational study of 140 patients who underwent freehand catheter placement, postoperative CT scan images were reviewed for accuracy of ventricular catheter placement.

\section{Methodology}

Study Design: This prospective,observational single center study was conducted in paediatric hydrocephalus patients $(<18$ years $)$ undergoing first time ventriculoperitoneal shunt placement for hydrocephalus, between September 2013 and August 2016 for a period of three (03) years.

Outcome Variables: The primary outcome was location of the ventricular catheter on the first postoperative imaging study.
Study Subjects: All the patients of CT proven Hydrocephalus who have been managed prospectively in paediatric neurosurgery department at National Institute of Neurosciences and Hospital (NINS), Dhaka, Bangladesh were included in study. Each patient had a precise chart review with multiple variables including age, sex, causes of hydrocephalus. All patients had postoperative brain $\mathrm{CT}$ scan imaging to reveal the accuracy of shunt placement.

Eligibility: Participating pediatric neurosurgeons were required to target the ipsilateral frontalhorn for all ventricular catheter placements.

All study patients met the inclusion criteria of clinical and radiographic evidence of hydrocephalus as determined by a pediatric neurosurgeon that requires a ventriculoperitoneal shunt, no prior history of shunt insertion or endoscopic third ventriculostomy for hydrocephalus, younger than 18 years of age at the time of shunt insertion. However, active CSF or abdominal infection.

Acute phase of bacterial and tubercular meningitis presenting as hydrocephalus were excluded from study, loculations within the ventricular system, hydranencephaly, alobar holoprosencephaly, or any other congenital anomaly of the brain that severely distorts the ventricular anatomy such that ventricular catheter location cannot be determined and other difficulties that would preclude follow-up at 1 year like terminal illness with life expectancy $<1$ year were excluded from this study.

Data Collection: From this population of patients, the data which were abstracted were age, sex, etiology of hydrocephalus, site of shunt (frontal or occipital), side of shunt either right or left and accuracy of ventricular catheter placement based on postoperative CT scan. An "accurate" ventricular catheter placement was credited when the tip of the ventricular catheter resided within the intended ventricle. All catheter placements in this study were intended for the ipsilateral ventricle. Accurate target was frontal horn, anterior to foramen of Monro; body, atrium and third ventricle also acceptable. Placement was considered inaccurate if the ventricular catheter tip resided in the contralateral ventricle, outside of the ventricular system in the parenchyma. The accuracy of each ventricular catheter placement was determined by documented tip position in each of the radiology reports from the postoperative $\mathrm{CT}$ scans. Each postoperative CT scan was then reviewed by a member of the study team to confirm that the assessment of the catheter tip agreed with the assessment documented in the radiology report. In all 
patients, the assessment of the study team was in accordance with the radiology report. The primary outcome was the location of the ventricular catheter tip on the first postoperative CT-scan. The ventricular catheter tip was defined as the proximal $2 \mathrm{~cm}$ of the catheter.

\section{Results}

A total of 140 first time VPshunt insertions were performed at NINS, Dhaka, Bangladesh in the paediatric neurosurgery department. All patients underwent follow-up CT scan imaging to determine ventricular catheter location. Most patients were neonates and infants at surgery. Mean age of all patients was 2.39 yearsand range 6 days to 13 years; however,74(52.86\%) patients were under 6 months and $94(67.14 \%)$ patients were under 1 year at surgery (Table 1). Regarding side,137(97.86\%) cases were in right side and $3(2.14 \%)$ cases were in left side. Regarding location of burr hole frontal was 1 case and occipital was in 139 cases.

Table 1: Age of Patients Undergoing Placement of VP Shunt during the Study Period

\begin{tabular}{lcc}
\hline Age group & Frequency & Percent \\
\hline 0 to 1 month & 13 & 9.28 \\
1 to 6 months & 61 & 43.57 \\
6 to12 months & 20 & 14.28 \\
1 to2 years & 13 & 9.28 \\
2 to3 years & 8 & 5.71 \\
3 to13 years & 25 & 17.85 \\
\hline
\end{tabular}

Female children were predominant; $47.15 \%$ cases were male and $52.85 \%$ cases were female (Table 2 ).

Table 2: Sex Distribution of Paeditric Patient with Hydrocephalus

\begin{tabular}{lcc}
\hline Gender & Frequency & Percent \\
\hline Male & 66 & $47.15 \%$ \\
Female & 74 & $52.85 \%$ \\
\hline
\end{tabular}

The most common causes of hydrocephalus were congenital aqueductal stenosis which was $60(42.80 \%)$ cases followed by posterior fossa tumour. Post meningitis hydrocephalusand myelomeningocele which were 20(14.28\%) cases, 18(12.85) cases and $19(13.57 \%)$ respectively. Most of the hydrocephalus were obstructive which $112(80 \%)$ cases was. Communicating hydrocephalus were in $18(12.85 \%)$ cases (Table 3).

On first postoperative CT-scan image 55(39.28\%) cases of ventricular catheter tip resided in frontal horn, $18(12.85 \%)$ cases ventricular catheter tip resided in body, $12(8.57 \%)$ cases ventricular catheter tip resided in trigone, $(10.71 \%$ ) cases of ventricular catheter tip resided in $3 \mathrm{rd}$ ventricle, $15(10.71 \%)$ cases of ventricular catheter tip resided in brain parenchyma and $39(27.86 \%)$ cases of ventricular catheter tip crossed the midline (Table 4).

Table 3: Aetiology of Hydrocephalus

\begin{tabular}{lcc}
\hline Cause of Hydrocephalus & Frequency & Percent \\
\hline Congenital Hydrocephalus/ & 60 & 42.86 \\
aqueductal stenosis & & \\
Post meningitis Hydrocephalus & 18 & 12.85 \\
Myelomeningocele & 19 & 13.57 \\
Posterior fossa Tumour & 20 & 14.28 \\
Supratentorialtumour & 11 & 7.85 \\
Dandy walker malfomation & 9 & 6.42 \\
Occipital encephalocele & 2 & 1.42 \\
Arachnoid cyst & 1 & 0.71 \\
\hline
\end{tabular}

Table 4: Overall Ventricular Catheter Location on First Postoperative CT-scan image

\begin{tabular}{lcc}
\hline Catheter Location & Frequency & Percent \\
\hline Frontal Horn & 55 & 39.28 \\
Body & 18 & 12.85 \\
Trigone & 12 & 8.57 \\
3rd Ventricle & 1 & 0.71 \\
Brain Parenchyma & 15 & 10.71 \\
Tip Crosses Midline & 39 & 27.86 \\
Total & $\mathbf{1 4 0}$ & $\mathbf{1 0 0 . 0}$ \\
\hline
\end{tabular}

In this study 140 ventricular catheters were freehand passed based on standard surface anatomy. 55 (39.28\%) of 140 freehand passed catheters were placed accurately. (Table4, 5) Ventricular catheter tip placement in body of lateral ventricle, trigone and 3rd ventricle were considered suboptimal and acceptable.31(22.14\%) ventricular catheter tip placement in brain parenchyma and contralateral side were considered inaccurate. In this study 54(38.57\%) ventricular tip placement were inaccurate (Table 5).

Table 5: Freehand Ventricular Catheter Placement

\begin{tabular}{lcc}
\hline Freehand Placement & Frequency & Percent \\
\hline Accurate & 55 & 39.28 \\
Suboptimal & 31 & 22.14 \\
Inaccurate & 54 & 38.57 \\
Total & $\mathbf{1 4 0}$ & $\mathbf{1 0 0 . 0}$ \\
\hline
\end{tabular}




\section{Discussion}

Cerebrospinal fluid diversion using VP shunt placement is one of the most commonly performed neurosurgical procedures and one that carries a significant risk of failure requiring revision. Previous data suggest that almost one third of adult patients undergoing CSF shunting will require revision ${ }^{12}$. Optimal catheter placement may help reduce the risk of shunt failure. Ultrasonic and stereotactic guidance significantly improve the accuracy of ventricular catheter placement in comparison with freehand placement using surface anatomical landmarks. Surprisingly, only $39.28 \%$ of catheters placed using the freehand technique were accurately placed in our study. The only factor identified in this study to be a risk factor for inaccurate placement was use of the freehand technique using standard anatomical landmarks. Among the freehand catheter placements, none of the factors identified in this study increased the risk of inaccurate placement. It is not surprising that the side of placement was not significant, but notably neither the location nor ventricular size. We found that placement is equally as likely to be inaccurate throughout the full range of ventricular size. While a $38.57 \%$ rate of inaccurate placement with the freehand technique appears to be exceptionally high, it is consistent with other published data.

Wilson et $\mathrm{al}^{13}$ reported that $55 \%$ of catheters were placed accurately in their study. Yamada et $\mathrm{al}^{1}$ found that $42.9 \%$ cases of catheters were placed accurately in their study. Jansonet $\mathrm{al}^{14}$ published that $43.9 \%$ cases of catheters were placed accurately in their study. Whitehead et $\mathrm{al}^{4}$ found that $49 \%$ of catheters were placed accurately in their study. Theodosopouloset $\mathrm{al}^{13}$ found that only $38 \%$ of catheters were optimally placed. Similarly, Lind et al. found that $56 \%$ of catheters were placed accurately in their study ${ }^{13}$.

These data, together with theirs, suggest that we likely underestimate the rate of catheter misplacement using the freehand technique. Ultimately, more accurate placement only matters if it leads to reduced failure rates. Previous data from the pediatric literature suggest that utilizing an endoscope to ensure accurate placement of the ventricular catheter leads to reduced proximal failure but does not decrease the overall rate of shunt failure ${ }^{10}$. Based on that data, we hypothesized that increased utilization of stereotactic and ultrasonic guidance with resultant increases in accuracy of placement would lead to reduced proximal catheter failure. Furthermore, there is some data to suggest that the use of programmable valves reduces shunt failure/revision ${ }^{13}$.

\section{Conclusion}

Mechanical malfunction and infection are the most significant problems associated with VP shunts for the treatment of hydrocephalus. Above all, a significant proportion of shunt failure was due to obstruction of the ventricular catheter, and accurate placement of the shunt catheter is highly important to reduce the incidence of shunt malfunction. Although image guidance offers a promising solution to lower the risk of inaccurate catheter placement, which could lead to lower premature failure of ventricular shunts, our review demonstrated that there is not yet a clear benefit of these technologies.

\section{References}

1. Yamada SM, Kitagawa R, Teramoto A. Relationship of the location of the ventricular catheter tip and function of the ventriculoperitoneal shunt. Journal of Clinical Neuroscience. 2013;20(1):99-101.

2. Korinek AM, Fulla-Oller L, Boch AL, Golmard JL, Hadiji B, Puybasset L. Morbidity of ventricular cerebrospinal fluid shunt surgery in adults: an 8-year study. Neurosurgery. 2011;68(4):985-95.

3. Villavicencio AT, Leveque JC, McGirt MJ, Hopkins JS, Fuchs HE, George TM. Comparison of revision rates following endoscopically versus nonendoscopically placed ventricular shunt catheters. Surgical neurology. 2003;59(5):375-9.

4. Whitehead WE, Riva-Cambrin J, Wellons JC, Kulkarni AV, Holubkov R, Illner A, et al. No significant improvement in the rate of accurate ventricular catheter location using ultrasound-guided CSF shunt insertion: a prospective, controlled study by the Hydrocephalus Clinical Research Network. Journal of Neurosurgery: Pediatrics. 2013;12(6):565-74.

5. Albright AL, Haines SJ, Taylor FH. Function of parietal and frontal shunts in childhood hydrocephalus. Journal of Neurosurgery. 1988;69(6):883-6.

6. Kestle JR, Drake JM, Cochrane DD, Milner R, Walker ML, Abbott R, Boop FA. Lack of benefit of endoscopic ventriculoperitoneal shunt insertion: a multicenter randomized trial. Journal of neurosurgery. 2003;98(2):284-90.

7. Lind CR, Tsai AM, Lind CJ, Law AJ. Ventricular catheter placement accuracy in non-stereotactic shunt surgery for hydrocephalus. Journal of Clinical Neuroscience. 2009;16(7):918-20.

8. Missori, S. Artizzu, M. Salvati P. Immediate postoperative CT to assess the correct positioning of a ventricular catheter. British journal of neurosurgery. 2000;14(1):44-5.

9. Shkolnik A, McLone DG. Intraoperative real-time ultrasonic guidance of ventricular shunt placement in infants. Radiology. 1981;141(2):515-7.

10. Wan KR, Toy JA, Wolfe R, Danks A. Factors affecting the accuracy of ventricular catheter placement. Journal of Clinical Neuroscience. 2011;18(4):485-8.

11. Singh K, Raj J, Tiwari DP. Conventional versus neuro-navigation guided shunt surgery. World Journal of Medical Research. 2013;2(6).

12. Reddy GK, Bollam P, Shi R, Guthikonda B, Nanda A. 
Management of adult hydrocephalus with ventriculoperitoneal shunts: long-term single-institution experience. Neurosurgery. 2011;69(4):774-81.

13. Wilson TJ, Stetler WR, Al-Holou WN, Sullivan SE. Comparison of the accuracy of ventricular catheter placement using freehand placement, ultrasonic guidance, and stereotactic neuronavigation. Journal of neurosurgery. 2013;119(1):66-70.

14. Janson CG, Romanova LG, Rudser KD, Haines SJ. Improvement in clinical outcomes following optimal targeting of brain ventricular catheters with intraoperative imaging. Journal of neurosurgery. 2014;120(3):684-96 